\title{
Reconstruction of Coracoclavicular Ligament with Endobutton and Sutures to Stabilize Acromioclavicular Joint: A Retrospective Clinical Study and Finite Element Analysis
}

kai ding ( $\nabla$ supermandk@126.com )

Changzhou First People's Hospital https://orcid.org/0000-0002-1735-1435

wen zhang

Soochow University

xi chen

Changzhou First People's Hospital

yi-ge zhang

Changzhou First People's Hospital

wen ge ding

Changzhou First People's Hospital

\section{Technical advance}

Keywords: acromioclavicular joint dislocation, horizontal stability, reduction loss, augmentation repair, finite element analysis

Posted Date: February 17th, 2021

DOI: https://doi.org/10.21203/rs.3.rs-241606/v1

License: (c) (1) This work is licensed under a Creative Commons Attribution 4.0 International License.

Read Full License 


\section{Abstract}

Acromioclavicular joint dislocation is a common sports injury disease, surgical treatment to restore the acromioclavicular joint stability, including stability and vertical stability level. However, vertical stability is often neglected. So we did a retrospective study enrolled 38 patients using Endobutton reconstruction and suture repair (Group A) with those using single Endobutton (Group B). The perioperative assessments contained coracoclavicular distance (CCD), Constant-Murley shoulder joint score, University of California at Los Angeles (UCLA) shoulder joint score and the difference between bilateral CCD 12 months postoperatively. The evaluation of group A was significantly better than group $B$. Constant-Murley scores and UCLA shoulder scores preoperatively were significantly higher than those after operation. The postoperative CCD of the two groups was lower than that before surgery. CCD between the affected shoulder and another postoperatively was no difference in group A, but was different in group B. The difference of postoperative CCD of the two groups was different. Afterward, we evaluated the stress and deformation around the acromioclavicular joint by finite element analysis and found that the stress dispersion and displacement reduction enhanced the stability of acromioclavicular joint. Thus, reconstruction of coracoclavicular ligament with Endobutton and sutures repair can increase the stability of acromioclavicular joint.

\section{Introduction}

Acromioclavicular joint dislocation is a common shoulder injury. The main injury mechanism is that direct or indirect violence of the shoulder joint causes the torn of acromioclavicular joint capsule and the damage of coracoclavicular ligament, leading to the displacement of the lateral end of the clavicle (1). According to Rockwood classification (2), the main types of acromioclavicular joint injury are divided into 5 types, among which type I and type II can be treated conservatively, type IV, V and VI need surgical intervention, and type III needs to consider the treatment plan according to the age, physical activity, symptoms and other conditions of patients (3). At present, there are many surgical treatments for acromioclavicular dislocation, including clavicular hook plate, acromioclavicular screw or Kirschner wire, coracoclavicular ring, coracoclavicular screw, coracoacromial ligament transfer, distal clavicle excision, autogenous or allogenic ligament or tendon transfer, coracoclavicular ligament repair or reconstruction (4, 5). With the development of the anatomy and biomechanics of acromioclavicular joint, rigid fixation has been gradually eliminated due to its high failure rate. Anatomical reconstruction of coracoclavicular ligament has become a popular method recommended by many scholars, including Endobutton mini steel plate, autogenous or allogeneic tendon, and rivet with suture (6). However, the importance of acromioclavicular ligament in maintaining joint stability has been ignored. Therefore, our method was to reconstruct coracoclavicular ligament using Endobutton mini steel plate and simultaneously reconstruct acromioclavicular ligament as well. In this study, we retrospectively compared the clinical efficacy of coracoclavicular ligament reconstruction using Endobutton plate combined with the reconstruction of acromioclavicular ligament with coracoclavicular ligament reconstruction using Endobutton plate alone, and validated it by the finite element analysis model based on CT data. 


\section{Materials And Methods \\ 2.1 General data}

We retrospectively analyzed 38 patients with acute acromioclavicular dislocation from 2016 to 2019, and divided them into two groups according to the treatment: group A: reconstruction of coracoclavicular ligament with Endobutton plate + reconstruction of acromioclavicular ligament; group B: reconstruction of coracoclavicular ligament with Endobutton plate alone. Both groups received surgical treatment in the Department of Orthopaedics, the first people's Hospital of Changzhou. Inclusion criteria: 1. Rockwood type III or V; 2 . There were no other injuries in the ipsilateral and contralateral limbs; 3 . Closed injury; 4. The time between injury and surgery was within 3 days; 5 . There was no history of shoulder disease. All surgeries were performed by surgeons from the same treatment team and all patients signed informed consent form. This study was approved by the Ethics Committee of our hospital and all patients signed informed consents.

All patients were classified according to Rockwood classification system based on the anterior and posterior X-ray images of the injured shoulder joint. The average age of the patients was $44.61 \pm$ 9.86 years. Among these patients, 18 cases involved the left shoulder and 20 cases involved the right shoulder. The causes of injuries included falls and accidents. There were 29 cases of Rockwood type III and 9 cases of type $V$ injury.

\subsection{Surgical techniques}

Surgical technique for group A: All patients received the surgery in supine position under general anesthesia. Before surgery, the patient's surgical area was padded up. The incision started from the corner of the acromion, slightly curved medially, and extended down the distal clavicle to the top of the coracoid process. The incision was about $8 \mathrm{~cm}$ long. The deltoid fascia and the upper surface tissue of the distal clavicle were split in parallel, and the attachment points of the anterior deltoid and the posterior trapezius were reserved. The articular disc of acromioclavicular joint that may affect the reduction was partially resected. The residual soft tissue around the acromioclavicular joint capsule that did not affect the surgical procedure was preserved as much as possible for the reconstruction of the acromioclavicular ligament. We used a self-designed coracoid tunnel positioning suture passer (Fig. 1) and a $2.5 \mathrm{~mm}$ drill bit to establish three bicortical bone tunnels at the middle point of the coracoid base, $40 \mathrm{~mm}$ superior to the medial side of the acromial end of clavicle and $15 \mathrm{~mm}$ anterior to the medial side of the acromial end of clavicle. Then a PDSII suture was passed through using a suture passer as the guide suture. Three ultrabraid \#2 sutures were successively passed through the middle two holes of the Endobutton plate and folded into six strands. After connecting to the guide suture, the first Endobutton plate was placed under the coracoid process, and the six strands of the suture were passed through the upper edge of the coracoid process tunnels, among which four strands passed through the tunnel inside the clavicle to reconstruct the conoid ligament, and the other two strands passed through the tunnel outside the clavicle to reconstruct the trapezoid ligament. The sutures passed through the Endobutton plate and were temperarily fixed at the two tunnel openings on the upper edge of the clavicle. After the final reduction of 
the acromioclavicular joint, the suture would be tightened and knotted. Two bicortical tunnels were drilled on acromial head of clavicle and acromion of scapula, and the remaining suture that passed through the clavicle tunnel was crossed and passed through the bone tunnels on acromial head of clavicle and acromion of scapula, so as to complete the suture preparation for acromioclavicular joint ligament. Finally, the acromioclavicular joint was exposed and reduced manually. A $2.0 \mathrm{~mm}$ Kirschner wire was used to fix the acromioclavicular joint temporarily, and slight over reduction was allowed. At the same time, the suture for coracoclavicular ligament reconstruction was tightened to complete coracoclavicular ligament reconstruction, and the suture for acromioclavicular ligament reconstruction was also tightened and knotted. The acromioclavicular joint capsule was sutured using the surrounding residual tissue, and the wound was washed and sutured layer by layer.

The surgical technique used for the reconstruction of coracoclavicular ligament in group B was similar to that in group A. The acromioclavicular joint capsule was simply sutured without special treatment, and no bone tunnel was established.

\subsection{Postoperative rehabilitation}

The treated shoulders of all patients were suspended and fixed with triangular bandages for 4 weeks. The affected shoulder began passive activities on the second day after the surgery. Active movement of the shoulder started two weeks later, with the range of movement within 90 degrees. After 4 weeks, nonweight bearing shoulder movement began, and the range of motion was gradually increased to over 90 degrees. The patients were allowed to resume routine life 8 weeks postoperatively and they were allowed to do normal exercise or physical activities 12 weeks after the surgery.

\subsection{Functional evaluation and follow-up}

Clinical and imaging follow-up was performed at 1 and 12 months after the surgery. No patient lost any follow-up visit. Constant-Murley shoulder function score and UCLA shoulder score were used to evaluate the clinical outcomes before and after the surgery. The anterior and posterior radiographs of acromioclavicular joint were taken and followed up immediately after the surgery. In order to check the maintenance of reduction, the distance between the injured coracoclavicular joint (CCD) was measured on preoperative and postoperative X-ray images. CCD referred to the vertical distance between the horizontal line of the top of the coracoclavicular process and the horizontal line of the top of the conical protuberance on the lower surface of the clavicle.

\subsection{Finite element analysis}

We carried out finite element analysis to compare the biomechanical stability of the two different surgical methods for acromioclavicular joint dislocation. Using two-dimensional CT data of volunteers and medical engineering software such as Mimics, Geomagic and Hypermesh, we obtained the finite element model of acromioclavicular joint. The acromioclavicular joint dislocation-related finite element analyses were searched and reviewed on PubMed. According to the research findings of Atmaca et al. (7), the material properties were attributed to each part of the model using HyperMesh software (Table 1), the 
dislocation of acromioclavicular joint was simulated, and two different surgical fixation methods were used. The three-dimensional finite element models of the two groups of internal fixation were given the same load and constraint conditions to simulate the inferior and superior movement, anterior and posterior movement and mixed movement of acromion of clavicle. Finally, the biomechanical properties of different surgical methods were compared and analyzed.(Fig. 2)

\subsection{Statistical analysis}

All measurement data were expressed as mean \pm standard deviation. All categorical data were compared using Fisher exact test. The normal distribution of all measurement data was analyzed using ShapiroWilk test. The intra-group difference of the results before and after surgery was identified using paired $t$ test, and the inter-group difference was identified using Mann-Whitney U test. SPSS23.0 software was used for statistical analysis, and $P<0.05$ was considered statistically significant.

\section{Results}

There was no statistical difference in the general data of all 38 patients (Table 1 ). The average follow-up time was $13.05 \pm 1.79$ months (range: $12-18$ months). In both group $A$ and $B$, the Constant shoulder score at the first and 12th months follow-up was higher than that before the surgery, and the difference was statistically significant $(P<0.05$, Table 3$)$. UCLA shoulder score at postoperative follow-up was also higher than that before the surgery, the difference was statistically significant $(P<0.05$, Table 4$)$. The postoperative CCD of the two groups was lower than that before the surgery, and the difference was statistically significant $(P<0.05)$, which indicated that the two treatment options both could reduce the acromioclavicular joint and restore the function of the shoulder joint (Table 5). At the same time, there was no statistical difference between the CCD of affected shoulder and the healthy shoulder in group A at 12 months postoperatively, while there was difference between the CCD of affected shoulder and the healthy shoulder in group B at 12 months postoperatively, which indicated that the incidence of joint reduction loss in group A was low one year postoperatively, and the CCD in group A was close to the normal CCD (Table 6). The difference of CCD at 12 months postoperatively between the two groups was statistically significant $(P<0.05)$ after eliminating self-control deviation, which showed that group A was better than group $B$ in maintaining the joint stability after surgical fixation of acromioclavicular joint dislocation (Table 7). The results of finite element analysis showed that: In normal physiological group, under the conditions of superior and inferior, anterior and posterior, and mixed movement loading, the deformation of distal clavicle was $2.13 \mathrm{~mm}, 2.56 \mathrm{~mm}$ and $4.29 \mathrm{~mm}$, respectively, and the stress of coracoid and clavicle suspension suture was $33.81 \mathrm{MPa}, 28.09 \mathrm{MPa}$ and $44.84 \mathrm{MPa}$, respectively. In the coracoclavicular ligament reconstruction using Endobutton alone group, the distal clavicle deformation was $2.44 \mathrm{~mm}, 5.29 \mathrm{~mm}$ and $6.64 \mathrm{~mm}$ under the three loading conditions, and the stress of the suspension suture was 217.97 MPa, 283.55 MPa and 497.26 MPa, respectively. In reconstruction of acromioclavicular ligament using Endobutton plate combined with reconstruction of coracoclavicular ligament group, under the three loading conditions, the distal clavicular deformation was $0.34 \mathrm{~mm}$, $0.27 \mathrm{~mm}$ and $0.49 \mathrm{~mm}$, and the stress of suspension suture was $222.66 \mathrm{MPa}, 193.21 \mathrm{MPa}$ and 
387.03 MPa, respectively (Table 8). The results showed that reconstruction of coracoclavicular ligament with Endobutton plate combined with the reconstruction of acromioclavicular ligament can increase the horizontal and vertical stability of the acromioclavicular joint, and solve the problems of gravity concentration, deformation and reduction loss caused by the reconstruction of coracoclavicular ligament with Endobutton plate alone. It also theoretically explained the reason for the low reduction loss rate in group A one year after the surgery.

\section{Discussion}

The surgical treatment of acromioclavicular joint dislocation is often very difficult because of its high failure rate, especially for high-level dislocation. The previous surgical methods such as Weaver-Dunn will cause a high unplanned secondary surgery rate (8). Therefore, at present, clinical researchers have proposed many methods to solve acromioclavicular joint dislocation, which can be divided into three categories: Endobutton plate suspension to reconstruct coracoclavicular ligament, hook plate or Kirschner wire rigid fixation and coracoclavicle + acromioclavicular joint capsule repair, among which hook plate or Kirschner wire rigid fixation is gradually eliminated due to its many postoperative and longterm complications and the need for secondary removal of internal fixation (8-10). At present, it remains controversy regarding the clinical application of Endobutton plate suspension surgery for the reduction of acromioclavicular dislocation. Through computer simulation of finite element analysis combined with biomechanical research, many scholars consider that additional augmentation suture repair of acromioclavicular ligament after reconstruction of coracoclavicular ligament can significantly improve the postoperative posterior displacement and rotation stability of acromioclavicular joint (11-13). However, some researchers carried out biomechanical analysis of cadaveric specimens simulating surgically treated acromioclavicular joint dislocation, and found that the effect of an additional acromioclavicular cerclage on the stability of acromioclavicular joint seemed to be negligible (14). Therefore, they do not recommend to use additional acromioclavicular cerclage. However, these studies are limited to cadaver specimens or computer simulation, and there are few reports on clinical follow-up studies combined with finite element simulation. In our study, we found that anatomical reconstruction of coracoclavicular ligament with Endobutton plate suspension combined with the reconstruction of acromioclavicular ligament is helpful to improve the horizontal and vertical stability of acromioclavicular joint, recover the function of acromioclavicular joint as soon as possible, effectively reduce surgical trauma, avoid secondary surgery to remove the internal fixation device, and improve the satisfaction of patients.

At present, there are big differences in the selection of surgical techniques for Endobutton plate suspension reconstruction, mainly including the following four aspects: 1 . Whether acromioclavicular joint capsule is concerned or not. 2. Differences in the selection of clavicle and coracoid process tunnels. 3. Differences in the selection of suspension materials. 4. The choice of open surgery or arthroscopic surgery. 
Most researchers pay more attention to coracoclavicular ligament than acromioclavicular ligament. In fact, acromioclavicular ligament is very important for the stability of acromioclavicular joint. In recent years, acromioclavicular ligament has gained more and more attention in clinical investigators. Many biomechanical studies have shown that although acromioclavicular ligament is thin, the superior and posterior articular ligaments can limit the posterior displacement of the distal clavicle, and the inferior articular ligament can limit the anterior displacement of the distal clavicle. When the acromioclavicular ligament is damaged, the anterior-posterior displacement of the distal clavicle increases significantly (15-18). Simultaneously, many clinical studies have confirmed the importance of acromioclavicular joint ligaments. Cisneros (19) believes that $20 \%$ of patients have acromioclavicular joint horizontal instability after surgery, and suggests to increase the augmentation repair of acromioclavicular joint ligament. In the treatment of chronic acromioclavicular joint dislocation, Jensen et al. (20) incised the acromioclavicular joint capsule to strengthen the repair of tendon while they were performing arthroscopy-assisted reconstruction of the coracoclavicular ligament, so as to increase the horizontal stability of acromioclavicular joint. Tauber et al. (21) compared anatomic triple-bundle coracoclavicular ligament and acromioclavicular ligament reconstruction using autologous tendon graft with nonanatomic singlebundle coracoclavicular ligament reconstruction using autologous tendon graft, and confirmed that triplebundle reconstruction enhanced the horizontal stability of acromioclavicular joint due to the additional repair of acromioclavicular ligament. These results suggest that surgeons should pay more attention to the importance of acromioclavicular ligament and repair acromioclavicular ligament while reconstructing coracoclavicular ligament.

The Endobutton plate was initially used to reconstruct the cruciate ligament of the knee joint, and then gradually became an implant for the surgical treatment of acromioclavicular joint dislocation. Many clinical investigators have used Endobutton plate for single-bundle coracoclavicular ligament reconstruction, and achieved some short-term therapeutic effects (22-25). However, with the in-depth anatomical study of the stable structure of the acromioclavicular joint, some researchers believe that double-bundle anatomical reconstruction is the key factor for postoperative stability of the acromioclavicular joint and it is necessary to reconstruct the two branches of the coracoclavicular ligament: the trapezoid ligament and the conus ligament. Some of these researchers used double-bundle reconstruction with two tunnels on both clavicle and coracoid process, or used autogenous tendon to bypass the base of coracoid process to form double-bundle ligament (26), which not only can increase the vertical stability of acromioclavicular joint after surgery, but also can enhance the horizontal stability of acromioclavicular joint to some extent $(27,28)$. However, it has been proposed that coracoid dualtunnel may greatly increase the risk of iatrogenic fracture and injury of brachial plexus nerve and blood vessels (22). Therefore, we chose to anatomically reconstruct the coracoclavicular ligament with doubletunnel on the clavicle and a single tunnel on the coracoid process. Through measuring fresh cadaver specimens, Rios et al. (29) found that the anatomic location of bone tunnel is very important for the reconstruction of coracoclavicular ligament. The tunnel on the conus ligament should be $30-45 \mathrm{~mm}$ medial to the acromioclavicular joint and posterior to the clavicle. The bone tunnel on the trapezium ligament should be $15 \mathrm{~mm}$ lateral to the conus tunnel, and more anterior compared with the conus tunnel, 
which can improve the stability and strength of the reconstructed structure. According to the intraoperative conditions of our patients, we chose $40 \mathrm{~mm}$ and $15 \mathrm{~mm}$ away from the acromion of clavicle as the start points of standard bone tunnels.

Regarding the selection of suspension materials, PDS suture, autogenous tendon, synthetic ligament, Endobutton loop are all commonly used suspension materials. However, PDS suture alone can easily cause iatrogenic fracture and osteolysis in the long run due to its cutting effect on the bone; autogenous tendon may enlarge the surgical area, increase related complications, and decrease the patients' satisfaction; synthetic ligament is easy to cause infection and rejection due to biocompatibility; because it is difficult to accurately measure the physiological distance of patients' coracoclavicular joints, it is very hard to choose the length of Endobutton's high-strength loop (18, 23, 30-33). Therefore, after comprehensive consideration, we chose No. 2 ultrabraid suture as the suspension material, combined with the use of mini steel plate to reduce some complications caused by the suspension material.

With the popularization of arthroscopy, arthroscopy-assisted reconstruction of ligament for acromioclavicular dislocation has been recommended by more and more surgeons. Under the arthroscope, the surface under the coracoid process can be observed clearly to provide a visual field for the establishment of bone tunnel, which is more conducive to the establishment of bone tunnel and the placement of steel plate $(34,35)$. Abdelrahman et al. (36) performed open surgery and arthroscopic repair of acromioclavicular dislocation and achieved good clinical outcome. However, the learning curve of arthroscopic technique is long, the cost of patients is high, and the operation time is longer. Gowd et al. (37) carried out a systematic review and meta-analysis and confirmed that there was no significant difference in reduction loss and related complications between open surgery and arthroscopic surgery for acromioclavicular joint dislocation. Moreover, arthroscopic repair of the acromioclavicular ligament is difficult, which requires additional incision and repair (20). Therefore, we believe that reconstruction of acromioclavicular joint under direct vision in a limited incision can also achieve satisfactory clinical outcome.

In addition, on the basis of clinical research, we carried out preliminary computer simulation biomechanical research using finite element analysis to verify the results of the clinical study. We have demonstrated that acromioclavicular ligament augmentation repair combined with coracoclavicular ligament mini plate suspension fixation is more stable than coracoclavicular ligament mini plate suspension fixation alone. This result is consistent with the results of multiple finite element analysisrelated literatures (11-13). The finite element analysis study supported and validated our clinical research conclusions from three aspects: 1 . The deformation of distal clavicle in coracoclavicular ligament reconstruction combined with acromioclavicular ligament reconstruction group was smaller than that in coracoclavicular ligament reconstruction alone group. 2. In the coracoclavicular ligament reconstruction alone group, the deformation of the distal clavicle in the horizontal direction was obvious, while the deformation of the distal clavicle decreased significantly after the additional reconstruction of the acromioclavicular ligament. 3. Under the mixed movement loading condition, the stress of the suspension suture between clavicle and coracoid process in the Endobutton reconstruction of 
coracoclavicular ligament combined with the reconstruction of acromioclavicular ligament group was lower than that in the coracoclavicular ligament reconstruction alone group. Because it is considered that the fixation fails when the deformation of the acromioclavicular joint is over $5 \mathrm{~mm}$, (38), these findings also support that reconstruction of coracoclavicular ligament with Endobutton plate alone cannot provide horizontal stability. At present, biomechanical analysis of cadaveric specimens and finite element analysis of computer simulation are the mainstream methods to study different surgical methods of acromioclavicular joint dislocation in vitro. The advantages of finite element analysis are non-invasive, low cost, high efficiency and scientific. However, its limitation lies in that the tests are carried out in vitro, which may not be able to completely duplicate the real in vivo situation. Therefore, after the retrospective analysis of clinical cases, we performed finite element analysis to verify our findings and achieved satisfactory results. As far as we know, this is the computer simulated finite element analysis combined with retrospective clinical study to explore the feasibility of surgical methods for acromioclavicular joint dislocation.

\section{Conclusions}

In this study, the retrospective clinical analysis confirmed that anatomical reconstruction of coracoclavicular ligament using Endobutton plate combined with the reconstruction of acromioclavicular ligament is helpful to improve the horizontal and vertical stability of acromioclavicular joint, restore shoulder function, reduce trauma and avoid secondary surgery. At the same time, the finite element analysis of computer simulation also elucidated the biomechanical basis of this combined surgical treatment method. Our study also had some limitations. The sample size of our study was small, the follow-up time was relatively short, and we were not able to perform biomechanical study using cadaver specimens. Therefore, future studies with increased sample size, mid-term follow-up results and biomechanical studies are necessary to systematically analyze the feasibility of this combined surgical option for the treatment of acromioclavicular joint dislocation in clinical application.

\section{Declarations}

\section{Funding}

The author received support from the National Natural Science Foundation of China for research, authorship, and publication of this article. (No.82072410)

\section{Conflicts of interest}

The author(s) declared no potential conflicts of interest with respect to the research, authorship and/or publication of this article.

\section{Ethics approval}


This retrospective chart review study involving human participants was in accordance with the ethical standards of the institutional and national research committee and with the 1964 Helsinki Declaration and its later amendments or comparable ethical standards. The Ethics Committee of the Third Affiliated Hospital of Soochow University approved this study.

\section{Consent to participate}

All patients signed informed consents.

\section{Consent for publication}

Not applicable.

\section{Availability of data and material}

All data generated or analysed during this study are included in this published article.

\section{Code availability}

Not applicable.

\section{Authors' contributions}

All authors contributed to the study conception and design. Material preparation, data collection and analysis were performed by Kai Ding, Wen Zhang, Yi-ge Zhang and Wen-ge Ding. The first draft of the manuscript was written by Kai Ding and all authors commented on previous versions of the manuscript. All authors read and approved the final manuscript.

\section{Acknowledgements}

The authors would like to acknowledge Zhang Wen for his assistance in finite element analysis. Funding from the National Natural Science Foundation of China(No.82072410) is gratefully acknowledged.

\section{References}

1. Macdonald PB, Lapointe P. Acromioclavicular and sternoclavicular joint injuries. Orthop Clin North Am. 2008;39(4):535 - 45, viii. doi:10.1016/j.ocl.2008.05.003.

2. Babhulkar A, Pawaskar A. Acromioclavicular joint dislocations. Curr Rev Musculoskelet Med. 2014;7(1):33-9. doi:10.1007/s12178-013-9199-2.

3. Dal Molin DC, Ribeiro FR, Filho RB, Filardi CS Jr, Tenor AC Jr, Stipp WN, et al. Posterosuperior Surgical Access Route for Treatment of Acromioclavicular Dislocations: Results from 84 Surgical Cases. Rev Bras Ortop. 2012;47(5):563-7. doi:10.1016/S2255-4971(15)30004-5.

4. Beitzel K, Cote MP, Apostolakos J, Solovyova O, Judson CH, Ziegler CG, et al. Current concepts in the treatment of acromioclavicular joint dislocations. Arthroscopy. 2013;29(2):387-97. 
doi:10.1016/j.arthro.2012.11.023.

5. Le Hanneur M, Delgrande D, Lafosse T, Werthel JD, Hardy P, Elhassan B. Triple-bundle anatomical reconstruction using the coracoacromial ligament and the short head of biceps tendon to stabilize chronic acromioclavicular joint dislocations: A cadaver feasibility study. Orthop Traumatol Surg Res. 2018;104(1):27-32. doi:10.1016/j.otsr.2017.11.003.

6. Moura DL, Reis ERA, Ferreira J, Capelao M, Braz Cardoso J. A combined technique for acromioclavicular reconstruction after acute dislocation - technical description and functional outcomes. Rev Bras Ortop. 2018;53(1):67-74. doi:10.1016/j.rboe.2017.03.008.

7. Atmaca H, Ugur L, Ozkan A, Grassi Mantelli A, Erzincanli F. Changes in the loadings on the shoulder girdle in the case of scapulothoracic fusion. Int J Med Robot. 2016;12(3):538-46. doi:10.1002/rcs.1683.

8. Moatshe G, Kruckeberg BM, Chahla J, Godin JA, Cinque ME, Provencher MT, et al. Acromioclavicular and Coracoclavicular Ligament Reconstruction for Acromioclavicular Joint Instability: A Systematic Review of Clinical and Radiographic Outcomes. Arthroscopy. 2018;34(6):1979-95 e8. doi:10.1016/j.arthro.2018.01.016.

9. Vrgoc G, Japjec M, Jurina P, Gulan G, Jankovic S, Sebecic B, et al. Operative treatment of acute acromioclavicular dislocations Rockwood III and V-Comparative study between K-wires combined with FiberTape((R)) vs. TightRope System((R)). Injury. 2015;46(Suppl 6):107-12. doi:10.1016/j.injury.2015.10.053.

10. Horst K, Garving C, Thometzki T, Lichte P, Knobe M, Dienstknecht T, et al. Comparative study on the treatment of Rockwood type III acute acromioclavicular dislocation: Clinical results from the TightRope((R)) technique vs. K-wire fixation. Orthop Traumatol Surg Res. 2017;103(2):171-6. doi:10.1016/j.otsr.2016.11.009.

11. Sumanont S, Nopamassiri S, Boonrod A, Apiwatanakul P, Boonrod A, Phornphutkul C. Acromioclavicular joint dislocation: a Dog Bone button fixation alone versus Dog Bone button fixation augmented with acromioclavicular repair-a finite element analysis study. Eur J Orthop Surg Traumatol. 2018;28(6):1095-101. doi:10.1007/s00590-018-2186-y.

12. Morikawa D, Mazzocca AD, Obopilwe E, Cote MP, Kia C, Johnson JD, et al. Reconstruction of the Acromioclavicular Ligament Complex Using Dermal Allograft: A Biomechanical Analysis. Arthroscopy. 2020;36(1):108-15. doi:10.1016/j.arthro.2019.07.021.

13. Civan O, Atmaca H, Ugur L. Biomechanical comparison of double versus triple button reconstruction techniques in patients with acromioclavicular joint dislocation. Int J Med Robot. 2020;16(1):e2057. doi:10.1002/rcs.2057.

14. Theopold J, Schobel T, Fischer JP, Loffler S, Osterhoff G, Schleifenbaum S, et al. Acromioclavicular joint reconstruction: an additional acromioclavicular cerclage does not improve horizontal stability in double coraco-clavicular tunnel technique. Knee Surg Sports Traumatol Arthrosc. 2019;27(12):382734. doi:10.1007/s00167-019-05674-1. 
15. Fauci F, Merolla G, Paladini P, Campi F, Porcellini G. Surgical treatment of chronic acromioclavicular dislocation with biologic graft vs synthetic ligament: a prospective randomized comparative study. J Orthop Traumatol. 2013;14(4):283-90. doi:10.1007/s10195-013-0242-2.

16. Li H, Wang C, Wang J, Wu K, Hang D. Restoration of horizontal stability in complete acromioclavicular joint separations: surgical technique and preliminary results. Eur J Med Res. 2013;18:42. doi:10.1186/2047-783X-18-42.

17. Mazzocca AD, Arciero RA, Bicos J. Evaluation and treatment of acromioclavicular joint injuries. Am J Sports Med. 2007;35(2):316-29. doi:10.1177/0363546506298022.

18. Triantafyllopoulos IK, Lampropoulou-Adamidou K, Schizas NP, Karadimas EV. Surgical treatment of acute type $\mathrm{V}$ acromioclavicular joint dislocations in professional athletes: an anatomic ligament reconstruction with synthetic implant augmentation. J Shoulder Elbow Surg. 2017;26(12):e369-e75. doi:10.1016/j.jse.2017.05.032.

19. Cisneros LN, Reiriz JS. Prevalence of remaining horizontal instability in high-grade acromioclavicular joint injuries surgically managed. Eur J Orthop Surg Traumatol. 2017;27(3):323-33.

doi:10.1007/s00590-016-1898-0.

20. Jensen G, Katthagen JC, Alvarado L, Lill H, Voigt C. Arthroscopically assisted stabilization of chronic AC-joint instabilities in GraftRope technique with an additive horizontal tendon augmentation. Arch Orthop Trauma Surg. 2013;133(6):841-51. doi:10.1007/s00402-013-1745-2.

21. Tauber M, Valler D, Lichtenberg S, Magosch P, Moroder P, Habermeyer P. Arthroscopic Stabilization of Chronic Acromioclavicular Joint Dislocations: Triple- Versus Single-Bundle Reconstruction. Am J Sports Med. 2016;44(2):482-9. doi:10.1177/0363546515615583.

22. Zhang L, Zhou X, Qi J, Zeng Y, Zhang S, Liu G, et al. Modified closed-loop double-endobutton technique for repair of rockwood type III acromioclavicular dislocation. Exp Ther Med. 2018;15(1):940-8. doi:10.3892/etm.2017.5487.

23. Aslani H, Mirzaee F, Zafarani Z, Salehi S. Modified Internal Fixation Technique for Acromio-Clavicular (AC) joint dislocation: The "Hidden Knot Technique". Arch Bone Jt Surg. 2018;6(1):81-4.

24. Struhl S, Wolfson TS. Continuous Loop Double Endobutton Reconstruction for Acromioclavicular Joint Dislocation. Am J Sports Med. 2015;43(10):2437-44. doi:10.1177/0363546515596409.

25. Xiong C, Lu Y, Wang Q, Chen G, Hu H, Lu Z. Anatomical principles for minimally invasive reconstruction of the acromioclavicular joint with anchors. Int Orthop. 2016;40(11):2317-24. doi:10.1007/s00264-016-3283-3.

26. Carofino BC, Mazzocca AD. The anatomic coracoclavicular ligament reconstruction: surgical technique and indications. J Shoulder Elbow Surg. 2010;19(2 Suppl):37-46. doi:10.1016/j.jse.2010.01.004.

27. Choi S, Lee TJ, Kim MK, Park JE, Kang H. Midterm results of coracoclavicular stabilization with double augmentation for acute acromioclavicular dislocation. Springerplus. 2016;5(1):1858. doi:10.1186/s40064-016-3527-0. 
28. Xue C, Song LJ, Zhang H, Tang GL, Li X, Fang JH. Truly anatomic coracoclavicular ligament reconstruction with 2 Endobutton devices for acute Rockwood type $V$ acromioclavicular joint dislocations. J Shoulder Elbow Surg. 2018;27(6):e196-202. doi:10.1016/j.jse.2017.12.015.

29. Rios CG, Arciero RA, Mazzocca AD. Anatomy of the clavicle and coracoid process for reconstruction of the coracoclavicular ligaments. Am J Sports Med. 2007;35(5):811-7. doi:10.1177/0363546506297536.

30. Zhu Y, Hsueh P, Zeng B, Chai Y, Zhang C, Chen Y, et al. A prospective study of coracoclavicular ligament reconstruction with autogenous peroneus longus tendon for acromioclavicular joint dislocations. J Shoulder Elbow Surg. 2018;27(6):e178-e88. doi:10.1016/j.jse.2017.12.009.

31. Kibler WB, Sciascia AD, Morris BJ, Dome DC. Treatment of Symptomatic Acromioclavicular Joint Instability by a Docking Technique: Clinical Indications, Surgical Technique, and Outcomes. Arthroscopy. 2017;33(4):696-708 e2. doi:10.1016/j.arthro.2016.08.023.

32. Chaudhary D, Jain V, Joshi D, Jain JK, Goyal A, Mehta N. Arthroscopic fixation for acute acromioclavicular joint disruption using the TightRope device. J Orthop Surg (Hong Kong). 2015;23(3):309-14. doi:10.1177/230949901502300310.

33. Motta P, Maderni A, Bruno L, Mariotti U. Suture rupture in acromioclavicular joint dislocations treated with flip buttons. Arthroscopy. 2011;27(2):294-8. doi:10.1016/j.arthro.2010.09.009.

34. Spoliti M, De Cupis M, Via AG, Oliva F. All arthroscopic stabilization of acute acromioclavicular joint dislocation with fiberwire and endobutton system. Muscles Ligaments Tendons J. 2014;4(4):398403.

35. Abat F, Sarasquete J, Natera LG, Calvo A, Perez-Espana M, Zurita N, et al. Biomechanical analysis of acromioclavicular joint dislocation repair using coracoclavicular suspension devices in two different configurations. J Orthop Traumatol. 2015;16(3):215-9. doi:10.1007/s10195-015-0346-y.

36. Abdelrahman AA, Ibrahim A, Abdelghaffar K, Ghandour TM, Eldib D. Open versus modified arthroscopic treatment of acute acromioclavicular dislocation using a single tight rope: randomized comparative study of clinical outcome and cost-effectiveness. J Shoulder Elbow Surg. 2019;28(11):2090-7. doi:10.1016/j.jse.2019.06.007.

37. Gowd AK, Liu JN, Cabarcas BC, Cvetanovich GL, Garcia GH, Manderle BJ, et al. Current Concepts in the Operative Management of Acromioclavicular Dislocations: A Systematic Review and Metaanalysis of Operative Techniques. Am J Sports Med. 2019;47(11):2745-58. doi:10.1177/0363546518795147.

38. Ladermann A, Gueorguiev B, Stimec B, Fasel J, Rothstock S, Hoffmeyer P. Acromioclavicular joint reconstruction: a comparative biomechanical study of three techniques. J Shoulder Elbow Surg. 2013;22(2):171-8. doi:10.1016/j.jse.2012.01.020.

\section{Tables}


Table 1

General data

\begin{tabular}{|c|c|c|c|}
\hline & Group $A(n=19)$ & Group $B(n=19)$ & $P$ value \\
\hline $\operatorname{Age}^{*}$ & $43.79 \pm 8.55$ & $45.42 \pm 11.19$ & $\nabla 0.05^{\mathrm{a}}$ \\
\hline \multicolumn{4}{|l|}{ Sex } \\
\hline Male & 14 & 11 & \multirow[t]{2}{*}{$\nabla 0.05^{\mathrm{a}}$} \\
\hline Female & 5 & 8 & \\
\hline \multicolumn{4}{|l|}{ Side } \\
\hline Left & 10 & 8 & \multirow[t]{2}{*}{$\otimes 0.05^{a}$} \\
\hline Right & 9 & 11 & \\
\hline \multicolumn{4}{|c|}{ Rockwood Type } \\
\hline III & 14 & 15 & \multirow[t]{2}{*}{$\nabla 0.05^{\mathrm{a}}$} \\
\hline V & 5 & 4 & \\
\hline
\end{tabular}

a: There was no significant difference in general data between the two groups.

Table 2

Material properties of different parts of the model

\begin{tabular}{|lll|}
\hline Model parts & Modulus of elasticity (MPa) & Poisson's ratio \\
\hline Scapula & 16000.0 & 0.3 \\
\hline Clavicle & 11000.0 & 0.3 \\
\hline Capsula Articularis Acromioclavicularis & 1.7 & 0.08 \\
\hline Internal fixation & 110000.0 & 0.3 \\
\hline Suture & 1200.0 & - \\
\hline
\end{tabular}

Table 3

Preoperative and postoperative results: Constant Score

\begin{tabular}{|c|c|c|c|c|}
\hline \multirow[t]{2}{*}{ Group } & \multirow[t]{2}{*}{ Preoperative } & \multicolumn{2}{|l|}{ Postoperative } & \multirow[t]{2}{*}{$P$ value } \\
\hline & & 1 month & 12 months & \\
\hline A & $40.74 \pm 3.35$ & $55.26 \pm 2.08$ & $95 \pm 1.67$ & 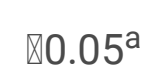 \\
\hline B & $42.11 \pm 2.13$ & $52.37 \pm 1.57$ & $84.11 \pm 1.52$ & $\otimes 0.05^{\mathrm{a}}$ \\
\hline
\end{tabular}


a: There was a significant difference between the preoperative and postoperative evaluation.

Table 4

Preoperative and postoperative results: UCLA Score

\begin{tabular}{|c|c|c|c|c|}
\hline \multirow[t]{2}{*}{ Group } & \multirow[t]{2}{*}{ Preoperative } & \multicolumn{2}{|c|}{ Postoperative } & \multirow[t]{2}{*}{$P$ value } \\
\hline & & 1 month & 12 months & \\
\hline A & $12.26 \pm 0.87$ & $16.74 \pm 0.99$ & $32.84 \pm 0.83$ & $\otimes 0.05^{\mathrm{a}}$ \\
\hline B & $12.16 \pm 0.9$ & $16.74 \pm 0.99$ & $26.95 \pm 1.54$ & $\otimes 0.05^{\mathrm{a}}$ \\
\hline
\end{tabular}

a: There was a significant difference between the preoperative and postoperative evaluation.

Table 5

Preoperative and postoperative results: CCD $(\mathrm{mm})$

\begin{tabular}{|c|c|c|c|c|}
\hline \multirow[t]{2}{*}{ Group } & \multirow[t]{2}{*}{ Preoperative } & \multicolumn{2}{|c|}{ Postoperative } & \multirow[t]{2}{*}{$P$ value } \\
\hline & & 1 month & 12 months & \\
\hline A & $11.46 \pm 3.26$ & $4.75 \pm 0.08$ & $4.77 \pm 0.79$ & $\otimes 0.05^{\mathrm{a}}$ \\
\hline B & $11.12 \pm 2.93$ & $5.75 \pm 0.18$ & $7.23 \pm 0.08$ & $\otimes 0.05^{a}$ \\
\hline
\end{tabular}

a: There was a significant difference between the preoperative and postoperative evaluation.

Table 6

Postoperative (12 months) and uninjured results:

CCD (mm)

\begin{tabular}{|llcc|}
\hline Group & Postoperative & Uninjured & $P$ value \\
\hline A & $4.78 \pm 0.02$ & $4.76 \pm 0.1$ & $0.083^{\mathrm{a}}$ \\
\hline B & $7.22 \pm 0.35$ & $4.81 \pm 0.07$ & $\varangle 0.05^{\mathrm{b}}$ \\
\hline \multicolumn{4}{|l}{ Data are shown as mean \pm standard deviation. } \\
\hline
\end{tabular}

a: There was no significant difference in CCD between postoperative side(12 months) and uninjured side in group $A$.

b: There was a significant difference in CCD between postoperative side(12 months) and uninjured side in group B. 
Table 7

Postoperative (12 months) results: The difference between the Postoperative CCD and that of the uninjured side $(\mathrm{mm})$

\begin{tabular}{|ll|}
\hline & Difference \\
\hline A & $0.02 \pm 0.37$ \\
\hline B & $2.42 \pm 0.33$ \\
\hline$P$ value & $\otimes 0.05^{\mathrm{a}}$ \\
\hline Data are shown as mean \pm standard deviation. \\
\hline
\end{tabular}

a: There was a significant difference in the difference between the Postoperative CCD and that of the uninjured side between group $A$ and group $B$.

Table 8

Comparison of stress and deformation of acromioclavicular joint in different groups

\begin{tabular}{|c|c|c|c|c|c|c|}
\hline \multirow[t]{2}{*}{ Group } & \multicolumn{3}{|c|}{ Deformation $(\mathrm{mm})^{a}$} & \multicolumn{3}{|l|}{ Stress (MPa) ${ }^{a}$} \\
\hline & Vertical(100N) & $\begin{array}{l}\text { Horizontal } \\
(100 \mathrm{~N})\end{array}$ & $\begin{array}{l}\text { Mix } \\
(100 N)\end{array}$ & Vertical(100N) & $\begin{array}{l}\text { Horizontal } \\
(100 \mathrm{~N})\end{array}$ & $\begin{array}{l}\text { Mix } \\
(100 N)\end{array}$ \\
\hline Normal & 2.13 & 2.56 & 4.29 & 33.81 & 28.09 & 44.84 \\
\hline $\begin{array}{l}\text { Single } \\
\text { Endobutton }\end{array}$ & 2.44 & 5.29 & 6.64 & 217.97 & 283.55 & 497.26 \\
\hline $\begin{array}{l}\text { Endobutton } \\
\text { Combined } \\
\text { with Suture }\end{array}$ & 0.34 & 0.27 & 0.49 & 222.66 & 193.21 & 387.03 \\
\hline
\end{tabular}

a: We applied a force of $100 \mathrm{~N}$ to the model from three directions and observe the deformation displacement distance and the change of stress value of the model.

\section{Figures}




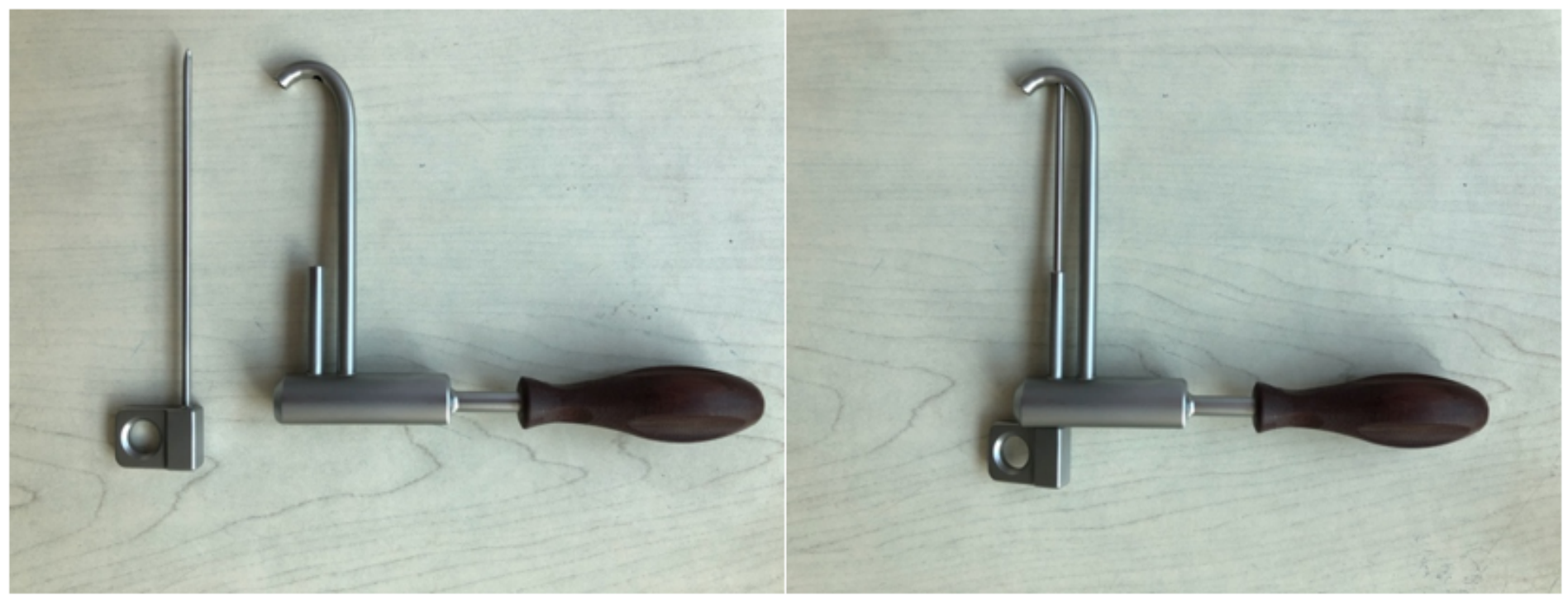

Figure 1

Self-designed positioning suture passer 
Deformation
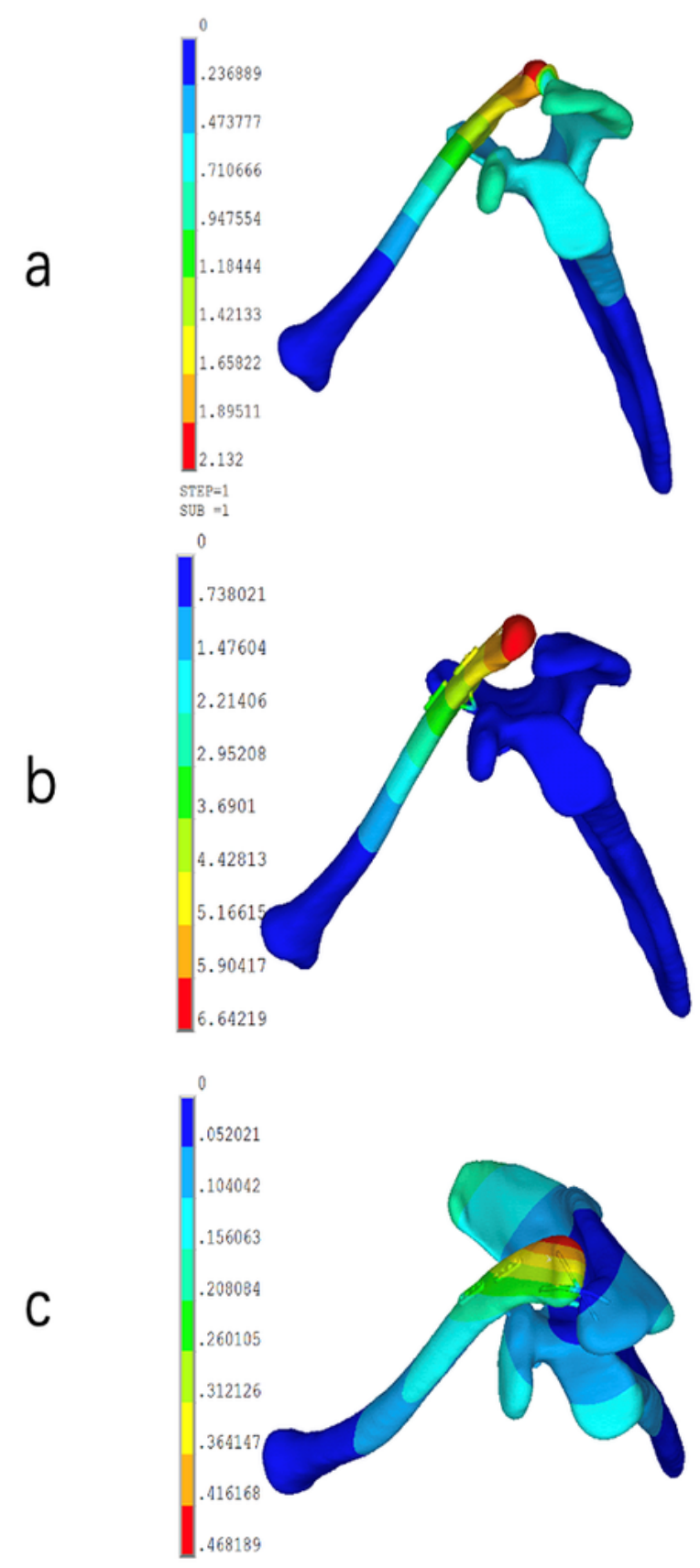

\section{Stress}
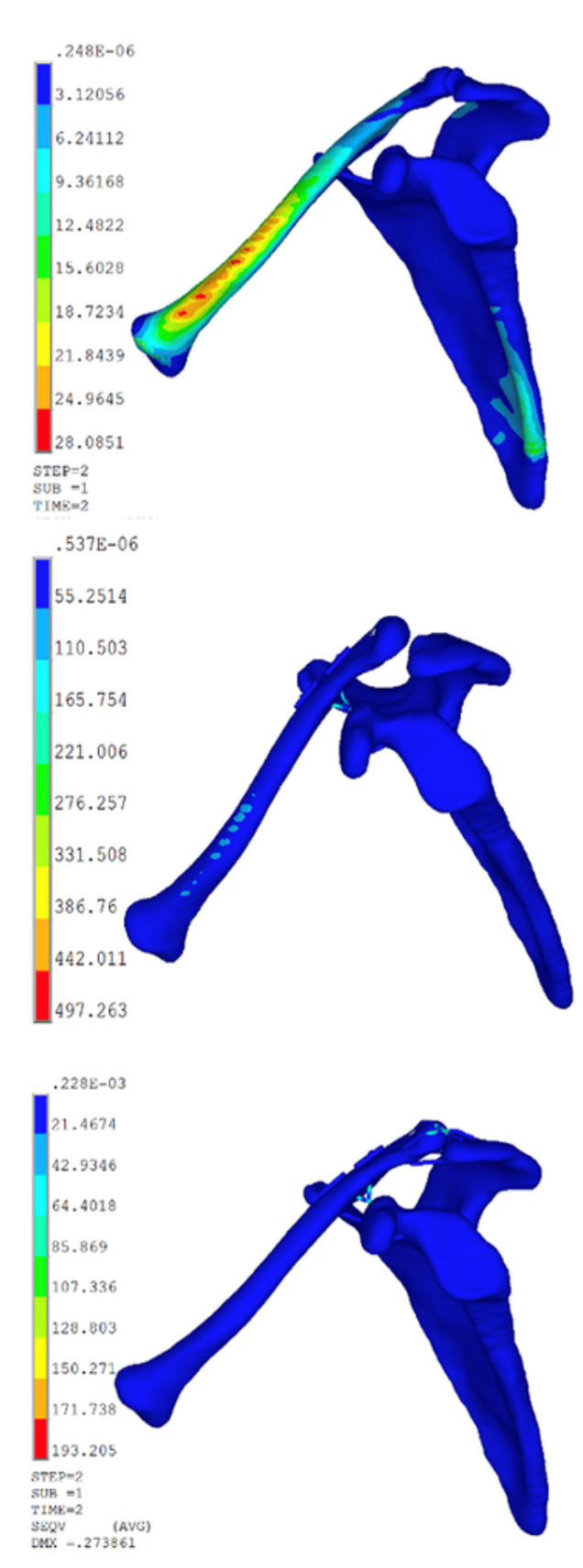

\section{Figure 2}

Simulation results of Ansys software: a: Normal group. b: Single Endobutton plate group. c: Endobutton plate combined with suture group. 

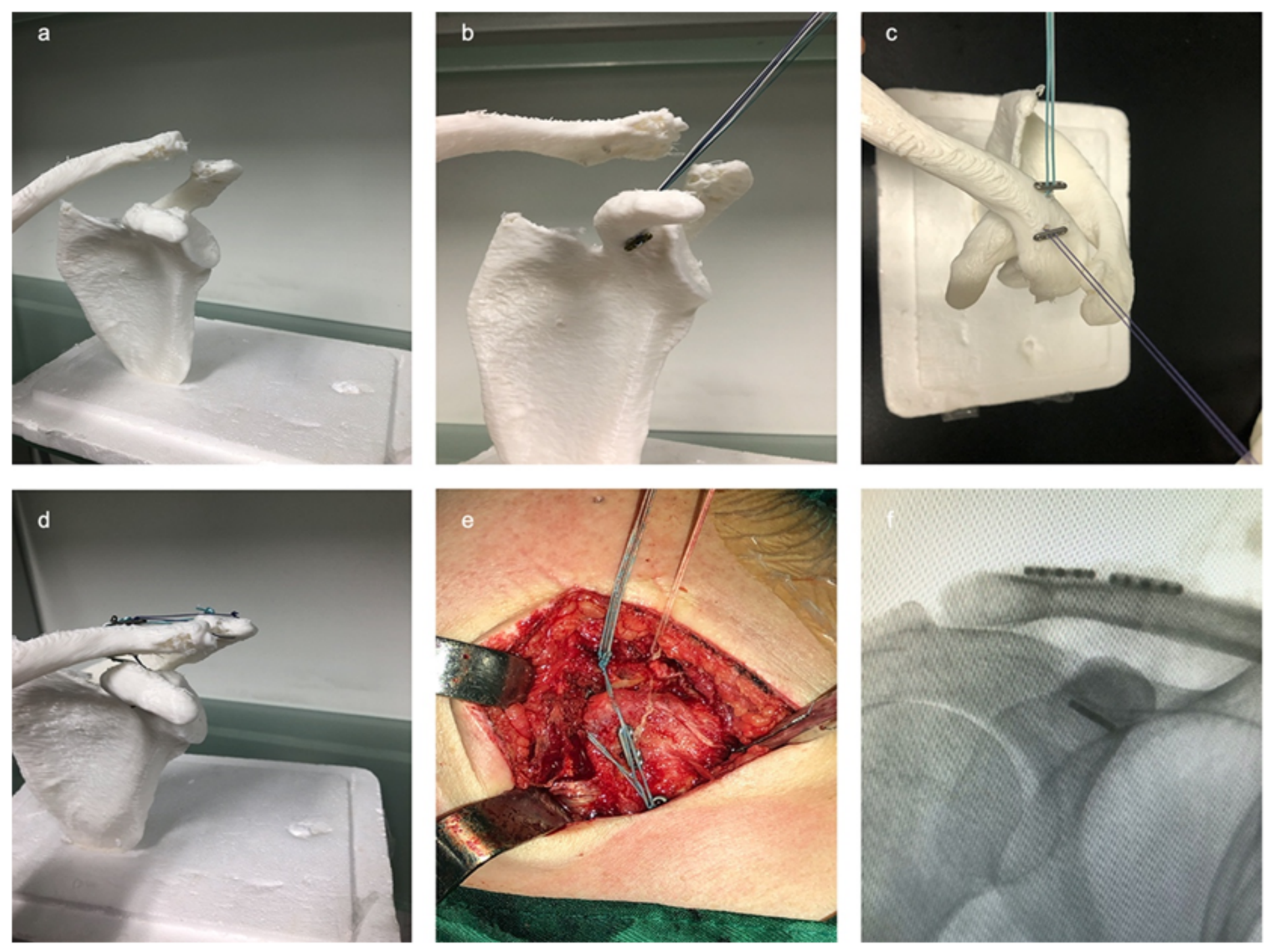

\section{Figure 3}

Schematic diagram and intraoperative results. a-d: Demonstrate the surgical procedure on a 3d printed model.e-f: Visual images and X-ray results during the surgery. 